\title{
SÁ, Guilherme José da Silva e. No mesmo galho: antropologia de coletivos humanos e animais
}

\section{Rafaella Eloy de Novaes}

\section{Q OpenEdition}

1 Journals

Edição electrónica

URL: http://journals.openedition.org/aa/548

DOI: 10.4000/aa.548

ISSN: 2357-738X

\section{Editora}

Programa de Pós-Graduação em Antropologia Social (UnB)

\section{Edição impressa}

Data de publição: 31 dezembro 2013

Paginação: 277-281

ISSN: 0102-4302

\section{Refêrencia eletrónica}

Rafaella Eloy de Novaes, «SÁ, Guilherme José da Silva e. No mesmo galho: antropologia de coletivos humanos e animais», Anuário Antropológico [Online], v.38 n.2 | 2013, posto online no dia 01 fevereiro 2014, consultado o 28 abril 2021. URL: http://journals.openedition.org/aa/548 ; DOI: https://doi.org/ $10.4000 /$ aa. 548

Este documento foi criado de forma automática no dia 28 abril 2021.

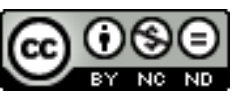

Anuário Antropológico is licensed under a Creative Commons Atribuição-Uso Não-Comercial-Proibição de realização de Obras Derivadas 4.0 International. 


\title{
SÁ, Guilherme José da Silva e. No mesmo galho: antropologia de coletivos humanos e animais
}

\author{
Rafaella Eloy de Novaes
}

\section{REFERÊNCIA}

SÁ, Guilherme José da Silva e. 2013. No mesmo galho: antropologia de coletivos humanos e animais. Rio de Janeiro: 7 Letras. 244 pp.

1 Por que relações intersubjetivas são, por vezes, aviltadas nas práticas científicas? Como narrar sobre relações intersubjetivas sem considerar aquelas que ocorrem no desenrolar de um estudo etnográfico? O grande aporte deste livro é a apresentação das relações intersubjetivas que se estabelecem em uma experiência etnográfica de observação por parte de um antropólogo de primatólogos observadores de primatas denominados muriquis. Os muriquis ou mono-carvoeiros são uma espécie de primata ameaçados de extinção, que habitam os 890 hectares de Mata Atlântica preservada no interior do estado de Minas Gerais, no Brasil. As relações intersubjetivas, aqui apresentadas, superam os padrões cientificistas fundamentados no distanciamento entre "sujeito" e "objeto" que parece não mais dar conta da realidade. "O condicionante agora é a capacidade do pesquisador de se mimetizar no contexto intersubjetivo, e não apenas camuflar-se na paisagem contando não ser percebido pelos seus interlocutores não humanos" (:148).

2 Estar no mesmo galho é experimentar apreender relações, encontrando afinidades e aproximações. Esta obra, resultado da tese de doutorado de Guilherme José da Silva e Sá, concluída em 2006 e defendida no Programa de Pós-Graduação em Antropologia Social da Universidade Federal do Rio de Janeiro, além da apresentação e da introdução, é composta por seis capítulos, respectivamente intitulados Quebra-Galhos; Grandes cafezais com uma mata no meio repleta de macacos e biólogos dentro; Macaco Hippie 
para Yuppie ver (ou too much monkey business); Histórias de primos (equi)distantes; Tomar ciência e fazer ciência; e Em busca do elo perdido.

3 A Fazenda Montes Claros, campo de estudo do autor, localiza-se no estado de Minas Gerais. Trata-se do habitat dos muriquis, subdivididos em dois macrogrupos: Matão e Jaó. Estes grupos são estudados por primatólogos e pesquisadores responsáveis por pesquisas de acompanhamento e monitoramento de primatas em longo prazo. 0 trabalho deles consiste em coletar ampla gama de dados sobre a alimentação e o comportamento destes animais, avaliando a sustentabilidade do ambiente para aquela população.

4 Dando especial ênfase às relações intersubjetivas que ocorrem em seu campo de pesquisa, seja entre ele e seus interlocutores animais humanos e não humanos, seja entre seus próprios interlocutores, o autor narra algumas situações que (des)nortearam o seu trabalho de campo, conforme indicado também em seu artigo intitulado "Estar ciente e fazer ciência sobre encontros e transformações" (2010). Por relações intersubjetivas, ele entende aquelas que se configuram em função de alguma troca experiencial entre sujeitos e que difere de uma projeção, que pressupõe ação de um sujeito sobre um objeto estático (:128).

5 Na primeira incursão do autor à mata, descrita em trecho de seu diário de campo transcrito no livro, enquanto caminhava com uma das biólogas/primatólogas, um dos muriquis atira-lhe um galho de árvore. Ao encolher-se com os olhos fixos no chão para proteger-se do galho que caíra, foi batizado em campo com urina de macaco (:21). Sim! Urina de macaco! Segundo a primatóloga, nosso autor foi ameaçado por Salomé [nome dado pelos primatólogos àquele muriqui] e, portanto, ele não deveria olhar para ela.

6 Talvez o leitor atento questione, com certo estranhamento, qual a importância de tal informação nesta experiência etnográfica. Asseguro que este contato inicial do autor com o muriqui ou, por que não ousar dizer, do muriqui com o autor, é de total relevância para a compreensão do modo como ele redige esta etnografia, cuja ênfase está no caráter poético das relações intersubjetivas que se estabelecem nas práticas antropológicas e científicas.

7 É ele mesmo quem nos instiga a pensar sobre o que é digno de ser publicado em um estudo. Por que nem tudo o que se vê em campo é passível de ser publicado? Por que nem toda relação intersubjetiva pode configurar-se na arena científica? (:170). Por que relações intersubjetivas não podem ser "predadas cientificamente" (nos termos de Bruno Latour)? Refiro-me às relações intersubjetivas que se estabelecem na pesquisa $\mathrm{e}$ que, diante da exigência de apresentação de dados "úteis" e "relevantes", são por vezes aviltadas na formação dos saberes a serem elencados naqueles compartimentos organizados de conhecimento de que nos fala Geertz (2012), dos quais se encontram fora os saberes construídos segundo uma lógica diferente da científica. De fato, o próprio estatuto do que é "útil" e "relevante" em uma pesquisa é aqui problematizado.

8 Nesta primeira incursão ao campo, embora tente ser neutro o máximo possível, no sentido de não atrapalhar o trabalho da bióloga/primatóloga que lhe mostrava a mata, parece que a presença do autor afetou profundamente o trabalho realizado por sua acompanhante, pois eles acabaram perdendo-se na mata por conta da intensa movimentação dos muriquis e de certo nervosismo da pesquisadora ao deparar-se com a observação do antropólogo às suas ações. Após conseguirem retornar ao local em que 
estavam os demais pesquisadores, esta inusitada situação de campo rendeu ao autor o apelido de curupira. ${ }^{1}$

9 Embora os primatólogos pesquisadores acreditassem na possibilidade da própria invisibilidade na mata e demandassem tal postura do autor, paradoxalmente houve um incômodo em se virem pesquisados por este último. Julgavam, inclusive, que a presença do antropólogo seria invasiva em relação aos seus pesquisados e que, como estranho na mata, os muriquis não o reconheceriam. Acreditava-se que Guilherme Sá usaria questionários e entrevistas em campo que atrapalhariam o trabalho dos primatólogos e, consequentemente, poderiam incomodar os muriquis. Tal situação despertou no autor a necessidade de rever instrumentos de pesquisa e apoiar-se exclusivamente no método da observação participante.

10 A tão procurada busca pela objetividade dos dados e pela naturalidade e neutralidade das ações dos objetos de estudo (seja primata, seja primatólogo), evidenciava a subjetividade nas relações pesquisador e pesquisado. Assim como apresenta a existência de relações intersubjetivas entre ele e os primatólogos e ainda, entre ele e os primatas, o autor mostra que a relação entre primatólogo e primata é também mutuamente percebida, ainda que na mata os primatólogos tenham por princípio utópico a sua própria invisibilidade no contato com os monos. Se na ótica dos primatólogos era preciso observar sem ser percebido, o autor ousa pensar que, com a presença dos primatólogos, toda ação dos primatas é uma reação, pois se faz tudo o que se fazia antes, mas com alguém olhando (:29).

11 De repente, o leitor tem à sua frente um antropólogo primata observando primatólogos - que também são primatas - observando primatas. Ou seria o contrário? - somos instigados pelo autor que, paulatinamente, nos conduz a pensar a respeito da postura do etnógrafo diante de seus pesquisados, alertando-nos quanto à importância das relações intersubjetivas de "nativos" e etnógrafos, personagens ativos em um mesmo galho (Sá, 2005). o que os primatas dos galhos das árvores estariam pensando de tudo aquilo? - devaneia nosso autor. Se é comum refletirmos sobre os efeitos da pesquisa etnográfica no campo em que ela é feita, aqui acompanhamos os efeitos do campo sobre o corpo do pesquisador na tomada de decisões a respeito dos caminhos que ele constrói para conduzir a sua pesquisa. A neutralidade cede lugar à simetria e ele é afetado pelo seu campo, tal como Jeanne Favret-Saada nos relata em "Ser afetado" (2005). A desconfiança e a curiosidade iniciais dos primatólogos acerca do trabalho do autor (sujeito) desaparecem quando ele se coloca diante dos outros/primatólogos (também sujeitos) como um igual (:37).

12 Se para estar na mata era preciso que os pesquisadores procurassem invisibilizar-se, os dados etnográficos apresentados por Guilherme Sá paulatinamente corroboram a existência de relações intersubjetivas, embora por vezes negadas pelos pesquisadores. Assim, em alusão ao comportamento pacifista dos hippies, os muriquis são vistos pelos pesquisadores como macacos hippies, pois, diferente dos demais primatas, são pacíficos, não brigam por comida e esperam sua vez de relacionar-se com as fêmeas. Mediante a categoria hippie, os muriquis são, portanto, aproximados do mundo dos humanos. A coesão grupal entre os muriquis se dá nos abraços coletivos, os quais eram, inclusive, encenados pelos pesquisadores, tornando-se uma espécie de cumprimento entre si. Estes abraços coletivos entre os muriquis, que outrora intimidavam os observadores, após a presença dos biólogos e dos primatólogos na mata, são vistos de outro modo, como uma espécie de manifestação de afetividade, evocando humanidade nos humanos. 
próprio sistema de nomeação dos muriquis na mata revela a existência de relações intersubjetivas. Anualmente, nascem filhotes muriquis na reserva e constitui tarefa dos pesquisadores indicar-lhes nomes que levem a inicial de seus próprios nomes. Atribuir aos primatas nomes humanos repletos de afecções e decorrentes de experiências cotidianas para o nomeador pressupõe relações intersubjetivas entre primatólogo e primata.

14

Embora contemple uma série de situações que indicam a existência de relações intersubjetivas no seu campo, o autor leva-nos a pensar que, na lógica científica, a relação entre primatólogo e primata exige que o primeiro transforme o segundo de primata-sujeito-floresta à primata-objeto-laboratório, tal como nos sugere a literatura de Bruno Latour a respeito da purificação científica. Transformar o muriqui em objeto parecia ser condição necessária para predá-lo cientificamente, por isso, era preciso negar a existência de relações intersubjetivas. Talvez o autor também pudesse dizer que transformar os primatólogos e seus demais interlocutores em objetos seria condição necessária para predá-los cientificamente. Entretanto, ele foge de tal cientificismo e este é, a meu ver, um dos grandes aportes da obra.

Essa fuga se deu quando se permitiu vivenciar a benéfica possibilidade de ser afetado em campo e desfrutar das relações intersubjetivas, colocando em suspeita o ideal de neutralidade científica - uma das égides sob a qual se sustenta a Ciência Moderna. Mediante as relações intersubjetivas entre primatólogos e primatas por ele apresentadas, somos convidados a pensar as relações entre pesquisador e pesquisado, o que se configura em uma das possibilidades de deslocamento da obra, cuja leitura pode ser extremamente proveitosa para aqueles que se dedicam à prática antropológica, mais especificamente ao estudo da antropologia da ciência. Todos primatas, todos nativos uns dos outros. Nativos de nós mesmos no ato de pesquisar. No mesmo galho é, portanto, um convite a uma antropologia da aproximação.

\section{BIBLIOGRAFIA}

FAVRET-SAADA, Jeanne. 2005 [1990]. "Ser afetado". Tradução de Paula de Siqueira Lopes. Cadernos de Campo, 13:155-161.

GEERTZ, Clifford. 2012. O saber local: novos ensaios em Antropologia Interpretativa. Rio de Janeiro: Vozes.

SÁ, Guilherme José da Silva e. 2010. "Estar ciente e fazer ciência: sobre encontros e transformações". Campos - Revista de Antropologia Social, 10 (1): 29-44. . 2005. “Meus macacos são vocês': Um antropólogo seguindo primatólogos em campo".

Revista Anthropológicas, 16 (2): 41-66.

Anuário Antropológico, v.38 n.2 | 2013 


\section{NOTAS}

1. 1. O curupira é uma figura temida pelos caboclos da região Amazônica, no Brasil. É considerado o guardião da floresta, protetor da fauna e da flora. Possui os pés virados para trás e o corpo cheio de pelos. Ele castiga severamente os caçadores e predadores da floresta, especialmente os caçadores e aqueles que caçam por puro prazer e não por necessidade de sobrevivência. Um dos mais conhecidos castigos aplicados aos homens é fazê-los se perderem na mata, sem conseguir encontrar o caminho de volta para casa. É o próprio Guilherme Sá quem se refere na obra com a alcunha de antropólogo curupira, não por castigar os humanos que predavam a mata, mas por contribuir, de certo modo, para que a sua companheira de incursão no campo, Catarina, se perdesse na mata, fato que, aliás, parece nunca ter acontecido antes, pois ela era tida como uma das primatólogas que mais conheciam a mata.

\section{AUTORES}

\section{RAFAELLA ELOY DE NOVAES}

PPGAS/UFG 